\title{
Be precise and suffer less pain! A comment on "A brief intervention utilising visual feedback reduces pain and enhances tactile acuity in CLBP patients"
}

\author{
Ali Khatibi ${ }^{\mathrm{a}, \mathrm{b}}$ \\ ${ }^{a}$ Department of Psychology, Bilkent University, Ankara, Turkey \\ ${ }^{\mathrm{b}}$ Interdisciplinary Program in Neuroscience, Bilkent University, Ankara-06800, Turkey \\ Tel.: +90 312290 6944; E-mail: ali.khatibi@gmail.com
}

A recent study by Trapp et al. [1] suggests that improvement in chronic low back pain (CLBP) patients' ability in sensory discrimination through a simple visu-sensory feedback intervention can contribute to the reduction of pain in those patients. Two groups of CLBP patients undergone standard physiotherapy treatment, a group of patients received additional intervention during which they could see the image of their back online while the experimenter was doing two point discrimination task and the other group received additional physiotherapy, relaxation and movement training. Results of this study showed that patients in the sensory discrimination training group's pain report were decreased in association with an improvement in their ability in their sensory discrimination ability while the other measure related to pain cognition remained unchanged.

These results at the first view remind us of a very recently suggested imprecision encoding hypothesis by Moseley and Vlaeyen [2]. In this model they take a different viewpoint of many other studies and consider pain as a conditioned response rather than a stimulus. They suggest that impairment in the precise encoding of multisensory information can lead people to overgeneralize their responses (i.e. pain) to a sensory in- put, which may itself contribute to the development of maldaptive behavior which may lead to the development of chronic pain $[3,4]$. On a similar path, the fearavoidance model predicts that imprecision in encoding may contribute to the acquisition of pain-related fear which also can contribute to development and maintenance of persistent pain problems [4]. In line with assumption of these models, results of the study by Trapp and colleagues showed that the learned fear through the imprecise association between sensory experience and pain can be changed through new learning. Precise encoding of sensory experiences in chronic low back pain patients helped them to reduce their pain.

There are a number of points that we think should be taken into account in the interpretation of Trapp et al. findings and can add to a better understanding of the mechanisms involved in the associative learning of pain-related fear and development of chronic pain. First, although researchers included some measures related to the cognitive aspects of pain, but a valuable and direct measure of fear of pain could contribute more to our understanding of change in cognitive aspects of pain among CLBP patients. In the future studies, it will be interesting to see how change in painrelated fear scores can influence change in pain among 
CLBP patients. Second, while the differences in pain measures' scores between two groups at the pretest was not significant, but the change in the pain anxiety symptom scale and the pain vigilance and awareness questionnaires scores shows two different patterns in two groups. Patients' scores in these measures at the group which received sensory discrimination training were decreased while the other group's scores were increased. Although, the choice of measures used in this study is not questionable and well-justified according to the goal of the study, it seems that with a bigger sample and with taking changes in scores between pretest and posttest into the model for the future analyses, we may have a better image of contribution of improvement in sensory discrimination ability to change in cognitive aspects of pain and reduction of perceived pain in patients. Third, the evaluation of patients' pain and sensory discrimination ability was performed in two time points which was clearly the main aim of the current study; for the future studies in will be an advantage to perform the evaluation in more time points during the treatment and also after the treatment for follow ups. It will help us to create a more dynamic image of change in sensory processing and pain and also will let us know more about the stability of patients' condition after stopping the treatment. In addition, a number of studies suggest that tactile acuity is altered in people in chronic pain [5], other neuroimaging studies suggest that functional connectivity at somatosensory cortex is altered in CLBP patients as compared to pain free individuals [6]; for the future it will be interesting to investigate the association between change in sensory discrimination threshold, tactile acuity and functional connectivity at the somatosensory cortex. It will help us to have an even wider image of involved neural networks in the process of change in the precise discrimination of sensory inputs and their contribution to the development of consequent fear responses and chronic pain.

\section{Conflict of interest}

None to report.

\section{References}

[1] Trapp W, Weinberger M, Erk S, Fuchs B, Mueller M, Gallhofer B, Hajak GO, K U Bler A, Lautenbacher S. A brief intervention utilising visual feedback reduces pain and enhances tactile acuity in CLBP patients. J Back Musculoskelet Rehabil 2015; 28(4): 651-660. DOI: 10.3233/BMR-140561.

[2] Moseley GL, Vlaeyen JW. Beyond nociception: the imprecision hypothesis of chronic pain. Pain. 2015 Jan; 156(1): 35-8.

[3] Zaman J, Vlaeyen JW, Van Oudenhove L, Wiech K, Van Diest I. Associative fear learning and perceptual discrimination: A perceptual pathway in the development of chronic pain. Neurosci Biobehav Rev. 2015 Jan 17. pii: S0149-7634(15)00011-1. doi: 10.1016/j.neubiorev.2015.01.009.

[4] Vlaeyen JW, Linton SJ. Fear-avoidance model of chronic musculoskeletal pain: 12 years on. Pain. 2012 Jun; 153(6): 1144-7.

[5] Catley MJ, O'Connell NE, Berryman C, Ayhan FF, Moseley GL. Is tactile acuity altered in people with chronic pain? A systematic review and meta-analysis. J PAIN 2014; 155: $985-$ 1000.

[6] Kong J, Spaeth RB, Wey HY, Cheetham A, Cookv AH, Jensen K, Tan Y, Liu H, Wang D, Loggia ML, Napadow V, Smoller JW, Wasan AD, Gollub RL. S1 is associated with chronic low back pain: A functional and structural MRI study. Mol Pain. 2013 Aug 21; 9: 43. 
Copyright of Journal of Back \& Musculoskeletal Rehabilitation is the property of IOS Press and its content may not be copied or emailed to multiple sites or posted to a listserv without the copyright holder's express written permission. However, users may print, download, or email articles for individual use. 